\title{
Genetic risk factors of cisplatin induced ototoxicity in adult patients
}

\author{
T. TALACH ${ }^{1}$, J. ROTTENBERG ${ }^{1}$, B. GAL ${ }^{1}$, R. KOSTRICA ${ }^{1}$, M. JURAJDA ${ }^{2, *}$, I. KOCAK ${ }^{3}$, R. LAKOMY ${ }^{3}$, E. VOGAZIANOS ${ }^{4}$
}

${ }^{1}$ Department of Otorhinolaryngology, Head and Neck Surgery, St. Anne's University Hospital Brno, Czech Republic; ${ }^{2}$ Department of Pathological Physiology, Faculty of Medicine, Masaryk University,Brno, Czech Republic; ${ }^{3}$ Department of Complex Oncology Care, Masaryk Memorial Cancer Institute, Brno, Czech Republic; ${ }^{4}$ Department of Otolaryngology, Dorset County Hospital NHS Foundation Trust, Dorchester, United Kingdom

*Correspondence: mjuraj@med.muni.cz

Received August 20, 2014 / Accepted September 14, 2015

\begin{abstract}
Ototoxicity is an important adverse effect of using Cisplatin (cis-diamminedichloroplatinum) (CDDP) as a form of chemotherapy. The clinical picture of CDDP induced ototoxicity includes perceptive hearing impairment (reversible or permanent) and tinnitus. Ototoxicity manifests with considerable variability between patients. The objective of this prospective study was to investigate a possible genetic background to this variability. We assessed ototoxicity induced by therapeutic doses of CDDP in adult patients with germinative testicular tumors, or other tumors treated with an identical CDDP dosage scheme. Audiological examination before, during and after the treatment has shown deterioration in hearing; first in the high-frequencies and with increased CDDP cumulative doses, impairment in other frequencies as well. Occurrence of tinnitus was not dependent on the administered dose of CDDP, or the other risk factors examined in this study. The association of CDDP induced ototoxicity with genetic polymorphisms in candidate genes was examined. Our study has demonstrated an association of early onset of CDDP induced ototoxicity with the presence of two copies of GSTT1 gene $(p=0,009)$ and with T allele of rs9332377 polymorphism in COMT gene ( $p=0,001)$.
\end{abstract}

Key words: cisplatin, ototoxicity, DNA copy number variations, single nucleotide polymorphisms

CDDP plays a key role in the treatment of testicular tumors, ovarian carcinoma, cervical cancer, bladder tumors, squamous-cell carcinoma of the head and neck, and lung carcinoma. In some diagnoses it is by necessity the treatment of choice, since it has no equivalent. Administration of CDDP produces serious adverse effects including nephrotoxicity and ototoxicity. By preventing CDDP nephrotoxicity, through hyper-hydration and therefore enhanced diuresis [1], the drug can be used in effective therapeutic doses to treat human malignancies. However ototoxicity following CDDP administration is another equally serious side-effect, due to the fact that its impacts are often permanent and more or less disabling. Presently, monitoring of the hearing function is not a standard part of diagnostic and therapeutic schemes of CDDP therapy [2]. Otoprotective medication is not established yet, though numerous recent studies have suggested promising results $[3,4]$.

Frequency analysis of the perceived sounds takes place on the mechanical level in the inner ear. High frequencies are analysed in the basal region of the cochlea, while lower frequencies are perceived, in a gradual ascending fashion, towards the apex. Damage to the organ of Corti caused by CDDP first becomes apparent in the area of the cochlea's basal turn; higher doses are needed to cause ototoxicity in the apical parts of cochlea $[3,4]$. The first signs of hearing loss can therefore be expected in the highest frequencies. This means that the hearing impairment is mostly found in the high-tone region of the audiogram. Since the analysis of high frequencies is essential for speech comprehension, their loss is the main factor leading to the disablement of the patient.

Hearing assessment can be performed by routine methods such as tone audiometry and examination using otoacoustic emissions, which are sensitive enough to detect the first signs of hearing impairment a long time before the patient starts to subjectively perceive the effects of ototoxicity $[5,6]$.

Pure tone audiometry (PTA) determines the auditory threshold of pure tones in the range of $125 \mathrm{~Hz}-8 \mathrm{kHz}$. This frequency range is considered essential for perceiving human speech [7]. For most patients the perception of the pure tones of higher frequencies is difficult because these are unfamiliar sounds and therefore difficult to recognize. Special equipment is necessary for high frequency audiometry. Since the damage 
to the organ of Corti caused by CDDP starts in the highest frequencies, it is necessary to find a reasonable compromise between the required sensitivity of the method and available technical means [8].

The mechanism of CDDP induced ototoxicity is oxidative stress caused by imbalance between production and removal of reactive oxygen species (ROS) and consequent induction of cell apoptosis upon activation of the enzymatic cascade of BCL-2, caspase 9 and 3 [9]. The adverse effects of ROS are blocked by a system of antioxidant enzymes. The antioxidant enzymes include glutathione peroxidase (GPx), glutathione reductase (GR), superoxiddismutase (SOD), glutathione-Stransferase (GST), $\gamma$-glutamylcystein-synthetase $(\gamma$-GCS) and catalase (CAT). Reactive radical metabolism also includes inducible nitric oxide synthase (iNOS) the inhibition of which leads to reduced CDDP nephrotoxicity in laboratory animals [10]. Factors of CDDP ototoxicity may also include mediators IL-1, IL-6 and TNF ${ }^{[11]}$. High levels of IL- 6 are often referred as linked to tumor resistance to CDDP treatment, while low levels are often associated with more frequent occurrence of toxic effects $[12,13]$. Recently, CDDP induced ototoxicity was associated with genetic polymorphisms found in the genes for catechol-O-methyl transferase (COMT) and thiopurin-S-methyl transferase (TPMT) [14]. The effect of these enzymes on CDDP toxicity can be explained by the regulation of CDDP bond to DNA through TPMT or through $\mathrm{S}$-adenosylmethionine, which is a common substrate for both TPMT and COMT [15].

Genes coding for GSTT1 and GSTM1 show whole gene deletions, which influence the expression and therefore the activity of these enzymes. The single nucleotide polymorphism (SNP) in the gene for GSTP1 (rs1695), results in the replacement of isoleucine for valine in position 105 . The variant with valine shows lower activity [16]. SNP rs4880 in gene for SOD2 causes the replacement of alanine for valine in position 16. The variant with valine reduces the production of functional tetramer SOD2 and is associated with e.g. lung carcinoma and dilatation cardiomyopathy [17]. SNP analysed in the gene for inducible nitric oxide synthase (iNOS) (rs2297518) causes the replacement of serine for leucine in position 608. Homozygotes carrying the allele with leucine show higher iNOS enzymatic activity related to

Table 1. Characteristics of the patient group

\begin{tabular}{lcc}
\hline & Total & $\mathrm{N}=55$ \\
\hline \multirow{2}{*}{ Gender } & Men & $52(95 \%)$ \\
& Women & $3(5 \%)$ \\
\hline Follow up (in days) & Median $(5-95$ percentil) & $273(20-1024)$ \\
\hline Age & Median $(5-95$ percentil) & $35(22-59)$ \\
\hline & C21 & $1(2 \%)$ \\
Diagnosis (ICD-10) & C300 & $1(2 \%)$ \\
& C320 & $1(2 \%)$ \\
& C435 & $4(7 \%)$ \\
& C621 & $48(87 \%)$ \\
\hline
\end{tabular}

higher NO levels, which may cause cytotoxic effect [18]. The SNP rs1800587 in the non-coding region of the IL-1 gene in position -886, influences expression of IL-1 [19]. The SNP rs1800796 in gene coding IL-6 in position -572 influences the activity of IL- 6 and consequently also some biochemical parameters of inflammatory response, such as CRP levels [20]. The SNP rs2279115 influences the expression of gene BCL-2, when AA genotype is associated with higher expression of BCL-2 protein and worse prognosis in patients with chronic lymphatic leukaemia [21, 22]. The SNP rs1944423 is located in BCL-2 gene in the potential binding site for transcription factors [23]. The promoter of the TNF alpha gene contains two SNP TNFA -308 G/A (rs1800629) and -238 G/A (rs361525). These promoter polymorphisms show an influence on expression of TNF alpha [24].

\section{Patients and methods}

The study protocol was approved by the Multidisciplinary Ethics' Committee of St. Anne's University Hospital Brno (www.fnusa.cz). Inclusion criteria were as follows: age over 18 years, signed informed consent, CDDP therapy with expected survival longer than 6 months, absence of other factors potentially predisposing to hearing impairment (such as pre-treatment history of long-term noise exposure) and history of middle ear diseases. Normal findings on otoscopic examination, normal hearing, or very mild sensorineural hearing loss (with hearing thresholds $\leq 35 \mathrm{~dB}$ in all frequencies between $125 \mathrm{~Hz}$ and $8 \mathrm{kHz}$ and $\leq 50 \mathrm{~dB}$ for frequencies over $8 \mathrm{kHz}$ were required).

A group of 52 men and 3 women, who underwent CDDP treatment at the Masaryk Memorial Cancer Institute Brno, was recruited, Table 1 . This group was characterised by homogeneity in terms of used therapeutic schemes and doses administered in the individual cycles. As a condition of entry into the study was the absence of pre-existing hearing disorders, therefore, mainly young men diagnosed with seminoma entered the study. This explains the very atypical distribution of sex and age seen in the study group.

The patients underwent one of the following chemotherapeutic schemes: BEP (bleomycin, etoposide, CDDP), EP (etoposide, CDDP), CVD (CDDP, vinblastine, dacarbazine), FU/CDDP (5-fluorouracil, CDDP) or CDDP in monotherapy. All these schemes were characterised by the same dose of CDDP $\left(80-100 \mathrm{mg} / \mathrm{m}^{2}\right)$ administered in every cycle. During the course of one cycle this dose was usually administered over a period of 5 days. The interval between consecutive cycles was 21 days.

The initial examination was performed $5-0$ days before administration of the first chemotherapy cycle, further examinations were scheduled for $2-5$ days after the end of chemotherapy administration in each cycle, 5 - 0 days before treatment administration in the following cycle, and 21 30 days after the end of chemotherapy. A final examination was performed $80-100$ days after the end of chemotherapy. 


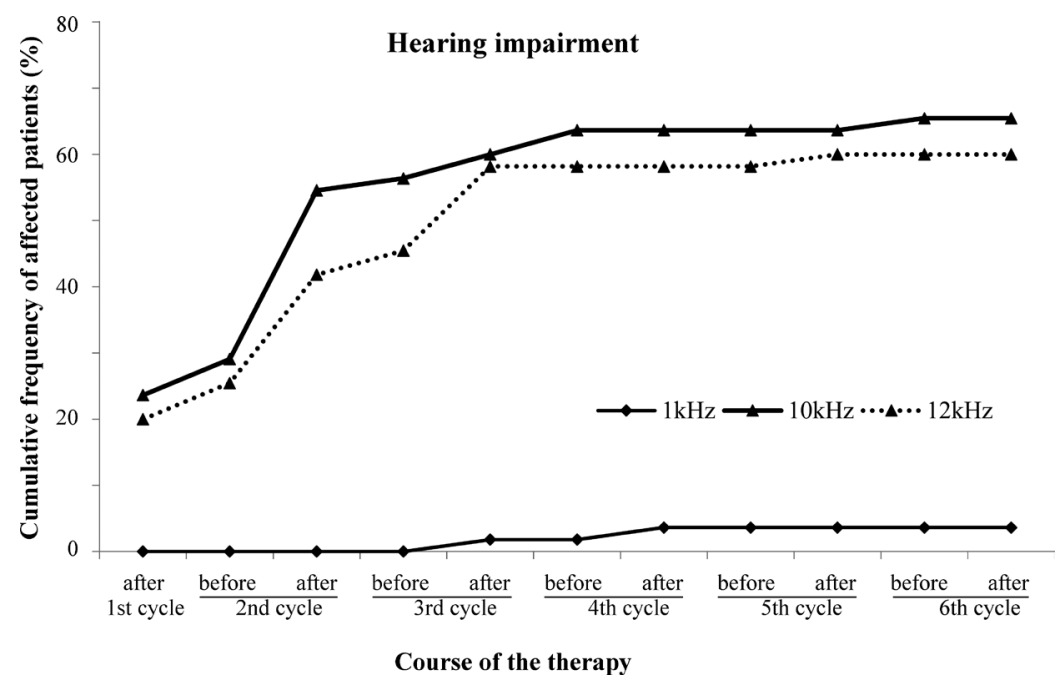

Figure 1. Progress of hearing impairment in the course of therapy $(\mathrm{N}=55)$

Audiometry. The hearing examination was carried out using high-frequency pure tone threshold audiometry (hfPTA) examining frequencies in the range of $125 \mathrm{~Hz}-12 \mathrm{kHz}$. Tinnitus was considered as a subjective symptom which was recorded as either worsened or not worsened after the treatment. HfPTA readings were performed in all patients using an audiometer Madsen Orbiter 922 and an Eymasa audiometric booth. Currently there is no universally acceptable classification of clinical manifestation of ototoxicity. Therefore, hearing loss representing ototoxicity was determined by adapting and simplifying "Muenster's classification", where worsening by $\geq$ $10 \mathrm{~dB}$ in $\geq 2$ examined frequencies or $\geq 15 \mathrm{~dB}$ in 1 examined frequency (as recorded by hfPTA examination) was considered as a manifestation of ototoxicity [25].

Genotyping. DNA was isolated from leukocytes taken from the venous blood sample obtained prior to the start of chemotherapy with S-Monovette (Sarstedt) tube system using EDTA as an anticoagulant. The DNA isolation was performed by NucleoSpin Blood XL (Mancherey-Nagel) isolation kit. The candidate genes for the study were selected following extensive literature review. The study focused on genes potentially involved in CDDP or ROS metabolism and cellular response to the damage. Gene polymorphisms with functional effect on gene products were preferred. Copy number variations of GSTT1 and GSTM1 candidate genes were detected using TaqMan Copy Number Assays Hs00010004_cn and Hs02575461_cn (Life Technologies). Allelic variants of candidate genes SNPs were detected using TaqMan Genotyping Assays (Life Technologies). Genotyping was carried out using a real time cycler ABI 7000 (Applied Biosystems).

The statistical evaluation was performed using STATISTICA (data analysis software system), version 12. StatSoft, Inc. (2013) www.statsoft.com.
The software MIDAS [26] was used to analyse possible linkage disequilibria between the alleles located on the same chromosome.

\section{Results}

In total 55 patients treated with CDDP were examined by audiometry and genotyped. Careful monitoring of tinnitus occurrence for the entire period of CDDP treatment showed no significant association with the administered CDDP dose, hearing impairment or patients' genotypes. The graph describing hearing impairment during the course of therapy shows a steep increase in the number of affected patients after the second cycle of chemotherapy, whereas additional cycles of chemotherapy do not show any further increase of hearing impairment Fig. 1 . This trend is especially apparent in hearing thresholds at high frequencies. That is why, we decided to analyse the progress of hearing impairment after each phase of the CDDP therapy, instead of the final results, following all cycles of CDDP.

Our data show that some of the patients' genotypes and allelic variants were significantly associated with manifestation of CDDP ototoxicity from the beginning of the therapy. The difference in CDDP induced ototoxicity between carriers of two copies of gene for GSTT1 and carriers of one or no copy was statistically significant before the second cycle of CDDP $(\mathrm{p}=0,009)$. The T allele of rs 9332377 polymorphism in the gene for COMT was associated with higher risk of early onset of ototoxicity $(p=0,001)$ before the second cycle of CDDP.

Statistically significant associations of the candidate gene polymorphisms with early hearing impairment after CDDP therapy are detailed in Table 2. The final status of hearing impairment recorded by audiometry performed $80-100$ days after chemotherapy did not associate with any alleles of GSTT1 
Table 2. Minor allele frequencies (MAF) of SNPs studied

\begin{tabular}{lccc}
\hline Gene Symbol & $\begin{array}{c}\text { NCBI SNP } \\
\text { Reference }\end{array}$ & $\begin{array}{c}\text { MAF } \\
\text { (our results) }\end{array}$ & $\begin{array}{c}\text { MAF } \\
\text { (European population } \\
\text { according to NCBI dbSNP) }\end{array}$ \\
\hline GSTP1 & rs1695 & G 0.28 & G 0.40 \\
NOS2 & rs2297518 & A 0.19 & A 0.17 \\
SOD2 & rs4880 & A 0.43 & C 0.45 \\
IL6;LOC541472 & rs1800796 & C 0.06 & C 0.04 \\
IL1A & rs1800587 & A 0.32 & A 0.25 \\
BCL2;KDSR & rs1944423 & A 0.25 & A 0.21 \\
LTB;LTA;TNF & rs361525 & A 0.02 & A 0.05 \\
LTB;TNF;LTA & rs1800629 & A 0.13 & A 0.17 \\
BCL2 & rs2279115 & G 0.46 & G 0.43 \\
ARVCF,COMT & rs9332377 & T 0.22 & T 0.16 \\
TPMT & rs12201199 & T 0.04 & T 0.05 \\
\hline
\end{tabular}

or COMT genes. All other genetic polymorphisms studied did not show any association with hearing impairment in CDDP treated patients during the whole course of the therapy. Minor allele frequencies (MAF) did not show any statistically significant differences from HapMap referred MAFs Table 3. Subjectively perceived onset or aggravation of tinnitus did not show any associations with the analysed parameters.

The possibility of linkage disequilibrium between the GSTT1 copy number variation and COMT SNP rs9332377 was tested by software MIDAS and the result strongly supports the absence of such a phenomenon $(D=0,13122$, $\left.\mathrm{r}^{2}=0,00308\right)$.

\section{Discussion}

In accordance with previously published data the deterioration of hearing, documented using hfPTA $[3,4,5,27,28]$, was detected at the early phases of the treatment.

The inter-patient sensitivity to manifestation of ototoxicity is highly variable and our objective was to determine the degree of genetic dependence of this sensitivity. This was a prospective study evaluating ototoxicity induced by therapeutic doses of cisplatin in patients with testicular cancer who were treated with the same dosing schedule of CDDP. That as well as ensuring a good status of hearing in all participating patients before the treatment was given, achieved high homogeneity of the group in terms of CDDP pharmacokinetics. This was crucial in the detection of early stages of ototoxicity.

While the link between long-term results of ototoxicity manifestation, genetic background coding the enzymes metabolizing reactive oxygen species (ROS) could not be established, we have found an interesting association between early onset of ototoxicity symptoms, genetic background coding the GST family enzymes and COMT.

The early onset of ototoxicity was associated with the presence of two copies of the gene coding GSTT1. This result agrees with the results of other, already published studies [29, 30] which stated that the presence of alleles coding for less active forms of GSTP1 as well as the deletion of the gene for GSTM1 were the protective factors against CDDP induced ototoxicity.

This dependence has no straightforward explanation as the GSTT1 glutathione-S-transferase has a higher activity and

Table 3. Comparison of grouped genotype and allele counts of selected genetic markers in GSTT1 and COMT gene between patients with and without worsened hearing by tone audiogram. Selection of the results.

\begin{tabular}{|c|c|c|c|c|c|c|c|c|c|}
\hline & & \multicolumn{8}{|c|}{ Worsened hearing by tone audiogram; examination according to $\mathrm{cycle}^{2}$} \\
\hline & & \multicolumn{2}{|c|}{ After $1^{\text {st }}$ cycle } & \multicolumn{2}{|c|}{ Before $2^{\text {nd }}$ cycle } & \multicolumn{2}{|c|}{ After $2^{\text {nd }}$ cycle } & \multicolumn{2}{|c|}{ Before $3^{\text {rd }}$ cycle } \\
\hline \multicolumn{2}{|c|}{ Genotype/allele ${ }^{1}$} & YES & NO & YES & NO & YES & NO & YES & NO \\
\hline \multirow[t]{2}{*}{ GSTT1 } & $+/+$ & $7(63.6 \%)$ & $14(32.6 \%)$ & $10(71.4 \%)$ & $11(28.2 \%)$ & $12(54.5 \%)$ & $8(26.7 \%)$ & $8(66.7 \%)$ & $6(24.0 \%)$ \\
\hline & $+/-\&-/-$ & $4(36.4 \%)$ & $29(67.4 \%)$ & $4(28.6 \%)$ & $28(71.8 \%)$ & $10(45.5 \%)$ & $22(73.3 \%)$ & $4(33.3 \%)$ & $19(76.0 \%)$ \\
\hline \multicolumn{2}{|l|}{$\mathrm{p}^{3}$} & \multicolumn{2}{|c|}{0.085} & \multicolumn{2}{|c|}{0.009} & \multicolumn{2}{|c|}{0.050} & \multicolumn{2}{|c|}{0.027} \\
\hline \multicolumn{2}{|c|}{ OR $(95 \% \mathrm{CI})^{4}$} & \multicolumn{2}{|c|}{$3.625(0.908 ; 14.470)$} & \multicolumn{2}{|c|}{$6.364(1.645 ; 24.624)$} & \multicolumn{2}{|c|}{$3.300(1.029 ; 10.588)$} & \multicolumn{2}{|c|}{$6.333(1.398 ; 28.697)$} \\
\hline \multirow[t]{2}{*}{ COMT } & CT\&TT & $7(63.6 \%)$ & $15(34.1 \%)$ & $11(78.6 \%)$ & $11(27.5 \%)$ & $14(63.6 \%)$ & $8(25.8 \%)$ & $9(75.0 \%)$ & $6(23.1 \%)$ \\
\hline & $\mathrm{CC}$ & $4(36.4 \%)$ & $29(65.9 \%)$ & $3(21.4 \%)$ & $29(72.5 \%)$ & $8(36.4 \%)$ & $23(74.2 \%)$ & $3(25.0 \%)$ & $20(76.9 \%)$ \\
\hline \multicolumn{2}{|l|}{$\mathrm{p}^{3}$} & \multicolumn{2}{|c|}{0.094} & \multicolumn{2}{|c|}{0.002} & \multicolumn{2}{|c|}{0.011} & \multicolumn{2}{|c|}{0.005} \\
\hline \multicolumn{2}{|c|}{ OR $(95 \% \mathrm{CI})^{4}$} & \multicolumn{2}{|c|}{$3.383(0.853 ; 13.416)$} & \multicolumn{2}{|c|}{$9.667(2.261 ; 41.337)$} & \multicolumn{2}{|c|}{$5.031(1.540 ; 16.439)$} & \multicolumn{2}{|c|}{$10.000(2.032 ; 49.215)$} \\
\hline \multirow[t]{2}{*}{ COMT } & allele $\mathrm{T}$ & $7(31.8 \%)$ & $17(19.3 \%)$ & $13(46.4 \%)$ & $11(13.8 \%)$ & $16(36.4 \%)$ & $8(12.9 \%)$ & $11(45.8 \%)$ & $6(11.5 \%)$ \\
\hline & allele C & $15(68.2 \%)$ & $71(80.7 \%)$ & $15(53.6 \%)$ & $69(86.3 \%)$ & $28(63.6 \%)$ & $54(87.1 \%)$ & $13(54.2 \%)$ & $46(88.5 \%)$ \\
\hline $\mathrm{p}^{3}$ & & \multicolumn{2}{|c|}{0.249} & \multicolumn{2}{|c|}{0.001} & \multicolumn{2}{|c|}{0.009} & \multicolumn{2}{|c|}{0.002} \\
\hline \multicolumn{2}{|c|}{ OR $(95 \% \mathrm{CI})^{4}$} & \multicolumn{2}{|c|}{$1.949(0.688 ; 5.523)$} & \multicolumn{2}{|c|}{$5.436(2.044 ; 14.456)$} & \multicolumn{2}{|c|}{$3.857(1.472 ; 10.110)$} & $6.487(2$. & ; 20.898) \\
\hline
\end{tabular}

${ }^{1}$ In the marker GSTT1 + stands for presence of allele; - stands for deletion of allele. One patient with genotype ++/+ was excluded from statistical evaluation ( $N=54$ patients after $1^{\text {st }}$ cycle). Marker COMT was evaluated in 55 patients (after $1^{\text {st }}$ cycle).

${ }^{2}$ The hearing impairment was evaluated during examination according to the cycle; YES stands for hearing impairment; NO stands for none hearing impairment beside initial hearing condition.

${ }^{3}$ The statistical significance was evaluated by Fisher's exact test.

${ }^{4}$ Odds ratio together with $95 \%$ confidence interval 
participates in CDDP detoxification as well as in the cellular defence against oxidative stress, which is induced by CDDP. Most authors explain this paradox by suggesting a competition for substrate. It is well known that patients with malignancies regularly suffer from nutritional deficiency which includes also the lack of glutathione necessary for GST to work. Therefore, the CDDP detoxification process and the metabolizing of ROS are prone to impairment in this case. The activity of GST also differs in various locations of the body depending on the metabolic turnover, which means that the glutathione might be consumed or redistributed to the tissues with higher metabolic activity. The final result in the case of a genotype consisting of two copies of GSTT1 might be the lack of glutathione in the sensory inner ear cells causing the impairment of detoxification of CDDP and ROS with a subsequently more serious picture of ototoxicity.

The same mechanism may also explain the difference between an early and a long-term manifestation of CDDP ototoxicity related to a genetic background of GST family enzymes. The less active form of the enzyme consumes its substrate more slowly, but continuing the treatment with cytostatic drugs could also worsen symptoms of malnutrition and cause the consumption of glutathione and impairment of CDDP and ROS detoxification. That is why it might be just a matter of time before ototoxicity induced hearing loss finally occurs.

The explanation of the association of COMT genetic polymorphism with CDDP induced ototoxicity seems to be analogical. Some authors explain the association of gene for COMT with CDDP ototoxicity, with the fact that Sadenosylmethionine is a common substrate for TPMT and COMT [15]. The plausible interpretation could also be that 4-methylcatechol demonstrates a neuro-protective effect in CDDP induced ototoxicity [12].

To some extent this study replicates previously published data but this time in adults, not children. Verification of findings in associated studies is important but often underestimated as many authors try to publish new original results whilst published data remains unconfirmed [31].

Despite the fact that the importance of our results is more theoretical than clinical, the logical explanation of our results may have a clinical application. If the weakest point of the protective and detoxifying mechanisms is the lack of substrate available for enzyme function, nutritional supplements containing substrate might improve the final outcome of CDDP induced ototoxicity as well as reduce other negative side effects of CDDP treatment. S-Adenosylmethionine (SAMe) which is commercially available in the USA is also reported to increase intracellular levels of glutathione [32], which can also be achieved by supplementation of vitamin D [33]. On the other hand, the increased level of substrates of antioxidant enzymes could also protect the tumor cells against cytostatic drug effects.

Acknowledgments: This paper was supported by a IGA MZCR grant (reference number NS/10101 - 4).

\section{References}

[1] HAYES DM, CVITKOVIC E, GOLBEY RB, SCHEINER E, HELSON L et al. High dose cis-platinum diammine dichloride: Amelioration of renal toxicity by mannitol diuresis. Cancer 1977; 39: 1372-1381, http://dx.doi.org/10.1002/1097-0142(197704)39:4<1372::AID-CNCR2820390404>3.0.CO;2-I

[2] NEUWELT EA, BROCK P. Critical need for international consensus on ototoxicity assessment criteria. J Clin Oncol. 2010; 28: 1630-2. http://dx.doi.org/10.1200/JCO.2009.26.7872

[3] LYNCH ED, GU R, PIERCE C, KIL J. Reduction of acute cisplatin ototoxicity and nephrotoxicity in rats by oral administration of allopurinol and ebselen. Hearing Research 2005; 201: 81-89 http://dx.doi.org/10.1016/j.heares.2004.08.002

[4] YUMUSAKHUYLU AC, YAZICI M, SARI M, BINNETOGLU S, KOSEMIHAL E et al. Protective role of resveratrol against cisplatin induced ototoxicity in guinea pigs. International Journal of Pediatric Otorhinolaryngology 2012;76: 404-8 http://dx.doi.org/10.1016/j.ijporl.2011.12.021

[5] KNIGHT KR, KRAEMER DF, WINTER C, NEUWELT EA. Early changes in auditory function as a result of platinum chemotherapy: use of extended high-frequency audiometry and evoked distortion product otoacoustic emissions. J Clin Oncol. 2007;25: 1190-5. http://dx.doi.org/10.1200/ LCO.2006.07.9723

[6] BIRO K, NOSZEK L, PREKOPP P, NAGYIVANYI K, GÉCZI $\mathrm{L}$, et al. Characteristics and risk factors of cisplatin-induced ototoxicity in testicular cancer patients detected by distortion product otoacoustic emission. Oncology. 2006;70: 177-84. http://dx.doi.org/10.1159/000093776

[7] KATZ J, GABBAY WL, GOLD S, MEDWETSKY L, RUTHRA. Handbook of clinical audiology. 1994; 455-458

[8] SINGH CHAUHAN R, SAXENA RK, VARSHEY S. The role of ultrahigh-frequency audiometry in the early detection of systemic drug-induced hearing loss. Ear Nose Throat J. 2011 May;90: 218-22.

[9] GARCIA-BERROCAL JR, NEVADO J, RAMIREZ-CAMACHO R, SANZ R, GONZALEZ-GARCIA JA et al. The anticancer drug cisplatin induces an intrinsic apoptotic pathway inside the inner ear. Br J Pharmacol. 2007;152: 1012-20. http://dx.doi.org/10.1038/sj.bjp.0707405

[10] CHIRINO YI, TRUJILLO J, SANCHEZ-GONZALEZ DJ, MARTINEZ-MARTINEZ CM, CRUZ C, et al. Selective iNOS inhibition reduces renal damage induced by cisplatin. Toxicol Lett. 2008;176: 48-57. http://dx.doi.org/10.1016/j. toxlet.2007.10.006

[11] SO H, KIM H, LEE JH, PARK C, KIM Y et al. Cisplatin cytotoxicity of auditory cells requires secretions of proinflammatory cytokines via activation of ERK and NF-kappaB. J Assoc Res Otolaryngol. 2007;8: 338-55. http://dx.doi. org/10.1007/s10162-007-0084-9

[12] CALLIZOT N, ANDRIAMBELOSON E, GLASS J, REVEL M, FERRO $P$ et al. Interleukin- 6 protects against paclitaxel, cisplatin and vincristine-induced neuropathies without impairing chemotherapeutic activity. Cancer Chemother Pharmacol. 2008 ;62: 995-1007. http://dx.doi.org/10.1007/s00280-008$\underline{0689-7}$ 
[13] MITAZAKI S, KATO N, SUTO M, HIRAIWA K, ABE S. Interleukin-6 deficiency accelerates cisplatin-induced acute renal failure but not systemic injury. Toxicology. 2009; 265: 115-21. http://dx.doi.org/10.1016/j.tox.2009.10.005

[14] ROSS CJ, KATZOV-ECKERT H, DUBE MP, BROOKS B, RASSEKH SR et al. Genetic variants in TPMT and COMT are associated with hearing loss in children receiving cisplatin chemotherapy. Nat Genet. 2009; 41: 1345-9. http://dx.doi. org/10.1038/ng.478

[15] PUSSEGODA KA. Genetic variants associated with cisplatininduced hearing loss. Clin Genet. 2010; 78: 33-5. http://dx.doi. org/10.1111/j.1399-0004.2010.01414 2.x

[16] ALLAN JM, WILD CP, ROLLINSON S, WILLETT EV, MOORMAN AV et al. Polymorphism in glutathione S-transferase P1 is associated with susceptibility to chemotherapy-induced leukemia. Proc Natl Acad Sci U S A. 2001; 98(20): 11592-7. Erratum in: Proc Natl Acad Sci U S A 2001; 98(: 15394

[17] ABE M, XIE W, REGAN MM, KING IB, STAMPFER MJ et al. Single-nucleotide polymorphisms within the antioxidant defence system and associations with aggressive prostate cancer. BJU Int. 2011; 107: 126-34. http://dx.doi.org/10.1111/j.1464410X.2010.09344.x

[18] WANG SS, DAVIS S, CERHAN JR, HARTGE P, SEVERSON RK et al. Polymorphisms in oxidative stress genes and risk for non-Hodgkin lymphoma. Carcinogenesis. 2006; 27: 1828-34 http://dx.doi.org/10.1093/carcin/bgl013

[19] UM JY, RIM HK, KIM SJ, KIM HL, HONG SH. Functional polymorphism of IL-1 alpha and its potential role in obesity in humans and mice. PLoS One. 2011;6: e29524 http://dx.doi. org/10.1371/journal.pone.0029524

[20] FERRARI SL, AHN-LUONG L, GARNERO P, HUMPHRIES SE, GREENSPAN SL. Two promoter polymorphisms regulating interleukin-6 gene expression are associated with circulating levels of $\mathrm{C}$-reactive protein and markers of bone resorption in postmenopausal women. J Clin Endocrinol Metab. 2003; 88: 255-9 http://dx.doi.org/10.1210/jc.2002$\underline{020092}$

[21] WOJCIK I, SZYBKA M, GOLANSKA E, RIESKE P, BLONSKI JZ et al. Abnormalities of the P53, MDM2, BCL2 and BAX genes in acute leukemias. Neoplasma. 2005; 52: 318-24

[22] NUCKEL H, FREY UH, BAU M, SELLMANN L, STANELLE $J$ et al. Association of a novel regulatory polymorphism $(-938 \mathrm{C}>\mathrm{A})$ in the BCL2 gene promoter with disease progression and survival in chronic lymphocytic leukemia. Blood. 2007; 109: 290-7 http://dx.doi.org/10.1182/blood-2006-03-007567

[23] MILANI L, GUPTA M, ANDERSEN M, DHAR S, FRYKNÄS $\mathrm{M}$ et al. Allelic imbalance in gene expression as a guide to cis-acting regulatory single nucleotide polymorphisms in cancer cells. Nucleic Acids Res. 2007; 35: e34 http://dx.doi. org/10.1093/nar/gkl1152

[24] KROEGER KM, CARVILLE KS, ABRAHAM LJ. The -308 tumor necrosis factor- $\alpha$ promoter polymorphism effects transcription. Mol Immunol. 1997; 34: 391-9. http://dx.doi. org/10.1016/S0161-5890(97)00052-7

[25] SCHMIDT CM, BARTHOLOMAUS E, DEUSTER D, HEINECKE A, DINNESEN AG. The „Muenster classification“ of high frequency hearing loss following cisplatin chemotherapy. HNO. 2007; 55: 299-306. http://dx.doi.org/10.1007/s00106005-1368-1

[26] GAUNT TR, RODRIGUEZ S, ZAPATA C, DAY IN. MIDAS: software for analysis and visualisation of interallelic disequilibrium between multiallelic markers. BMC Bioinformatics. 2006;7: 227 http://dx.doi.org/10.1186/1471-2105-7-227

[27] SINGH CHAUHAN R, SAXENA RK, VARSHEY S. The role of ultrahigh-frequency audiometry in the early detection of systemic drug-induced hearing loss. Ear Nose Throat J. 2011; 90: 218-22.

[28] YILMAZ S, OKTEM F, KARAMAN E. Detection of cisplatin-induced ototoxicity with transient evoked otoacoustic emission test before pure tone audiometer. [Eur Arch Otorhinolaryngol. 2010; 267: 1041-4. http://dx.doi.org/10.1007/ s00405-009-1165-7

[29] OLDENBURG J, KRAGGERUD SM, BRYDØY M, CVANCAROVA M, LOTHE RA et al. Association between long-term neuro-toxicities in testicular cancer survivors and polymorphisms in glutathione-s-transferase-P1 and -M1, a retrospective cross sectional study. J Transl Med. 2007; 5: 70. http://dx.doi.org/10.1186/1479-5876-5-70

[30] OLDENBURG J, KRAGGERUD SM, CVANCAROVA M, LOTHE RA, FOSSA SD. Cisplatin-induced long-term hearing impairment is associated with specific glutathione s-transferase genotypes in testicular cancer survivors. J Clin Oncol. 2007; 25: 708-14. http://dx.doi.org/10.1200/ LCO.2006.08.9599

[31] BODDY AV. Genetics of cisplatin ototoxicity: confirming the unexplained? Clin Pharmacol Ther. 2013; 94: 198-200. http:// dx.doi.org/10.1038/clpt.2013.116

[32] LIEBER CS. S-adenosyl-L-methionine: its role in the treatment of liver disorders. The American journal of clinical nutrition 2002; 76: 1183S-7S

[33] GARCION, E, WION-BARBOT N, MONTERO-MENEI C, BERGER F, WION D. New clues about vitamin D functions in the nervous system. Trends in Endocrinology and Metabolism 2002; 13: 100-105 http://dx.doi.org/10.1016/ $\underline{\text { S1043-2760(01)00547-1 }}$ 